\title{
The study of the bathtub's heat dissipation based on heat transfer theory \\ Qing Liu ${ }^{1, \text { a }}$ \\ ${ }^{1}$ School of North China Electric Power University, 071000, China. \\ a756064199@qq.com
}

Keywords: Bathtub, Beat Dissipation, Heat Transfer Theory

Abstract. Several mathematical models are proposed to determine the shapes of bathtub and manipulative time, which are not only related to the heat source, the maximum capacity and volume of water, but also the motions of user and ingredients of water.

\section{Introduction}

With the development of electronic technology, the bathtub is becoming more and more popular. What we should pay attention to is the optimizing performances. The users focus on not only the comfort level, but also the degree of automation. In addition, for the lack of earth energy, we should make full use of the fresh water.

This paper analyze the relationship between the volume of water and temperature. The surface area of bathtub wall is linked to the volume of water and it affects the heat conduction between water and the air. Consider of this conditions, we build a model to reflects these influence.

\section{Setting up the Modeling}

\subsection{The model of bubble}

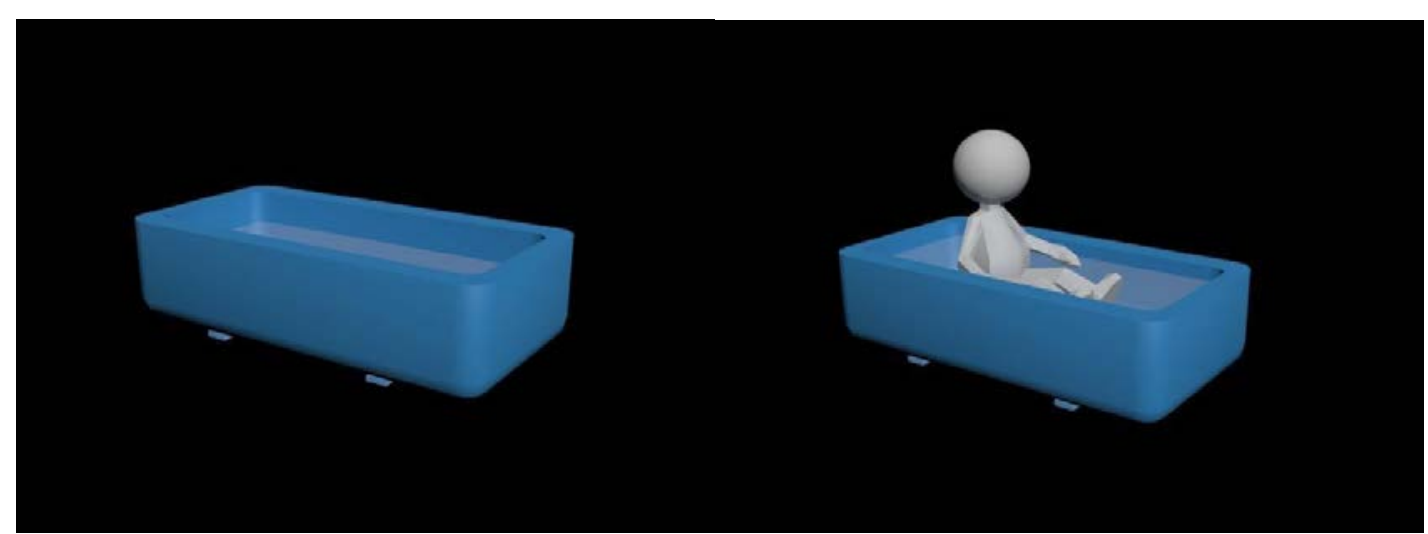

Figure1 the bathtub with water

Figure2 the bathtub with person and water

\subsection{Assumptions}

a) The temperature of the air is invariant.

b) All parts of thickness of bathtub wall are same and they are constant.

c) The temperature of changing procession is same as the initial one.

d) The temperature of the water in one bathtub is equal.

\subsection{The change of temperature}

We pour defined temperature (T1) water .After a time, water cools to T min.

The heat loss of the bathtub in unit time: Q1

According to the formula [1]

$$
\mathrm{Q}_{1}=-\beta \frac{-\mathrm{T} 0-\mathrm{T} 1}{\mathrm{~d}} \mathrm{~S} ;
$$

When button is rectangle $S=2(a h+b h)$; 
When button is roundness $S=2 \pi r h$.

The heat loss of the surface of water in unit time: $Q_{2}$

$$
\begin{gathered}
\mathrm{Nu}=\mathrm{c}(\mathrm{Gr} \times \mathrm{Pr})^{\mathrm{n}} \\
\mathrm{h}=\mathrm{Nu} \frac{\beta}{\mathrm{H}} \\
\mathrm{Q}_{2}=-\mathrm{h}(\mathrm{T}-\mathrm{T} 1)
\end{gathered}
$$

We can look up the table [2] to find c and $n$ which adapt to Tm.

Overall heat loss: $\mathrm{Q}$

$$
\mathrm{Q}=\mathrm{Q}_{1}+\mathrm{Q}_{2}
$$

Calculating the temperature in a random time $(\mathrm{t})$ :

$$
\begin{aligned}
& \mathrm{Qt}=\mathrm{Cm} 1 \frac{\mathrm{dT}}{\mathrm{dt}} \\
& \mathrm{T}=\mathrm{T}(\mathrm{t}=0)
\end{aligned}
$$

i.e. $\mathrm{T}=\frac{\mathrm{Qt}}{c m}+\mathrm{T} 0$.

We simulate leaner figures in different initial temperature. And we divide it into two states. One is the button of bathtub is rectangle, the other is the button of bathtub is roundness.



Figure3 In consideration of different initial temperature, the relationship between $t$ and $\mathrm{T}$, the button of bathtub is rectangle.

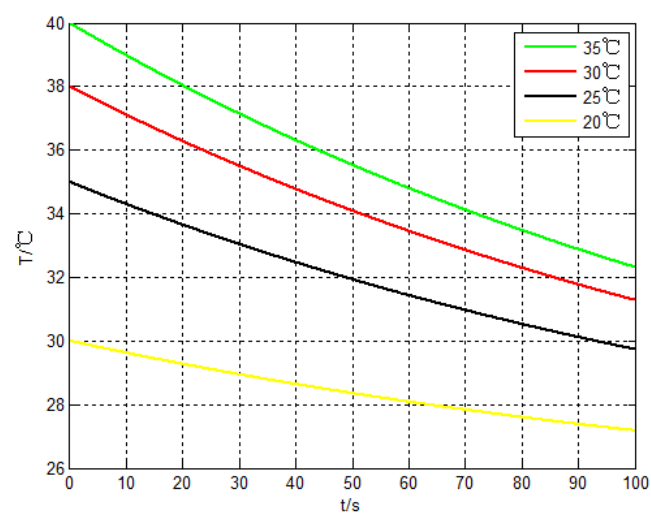

Figure4 the intercept graph of Figure2 


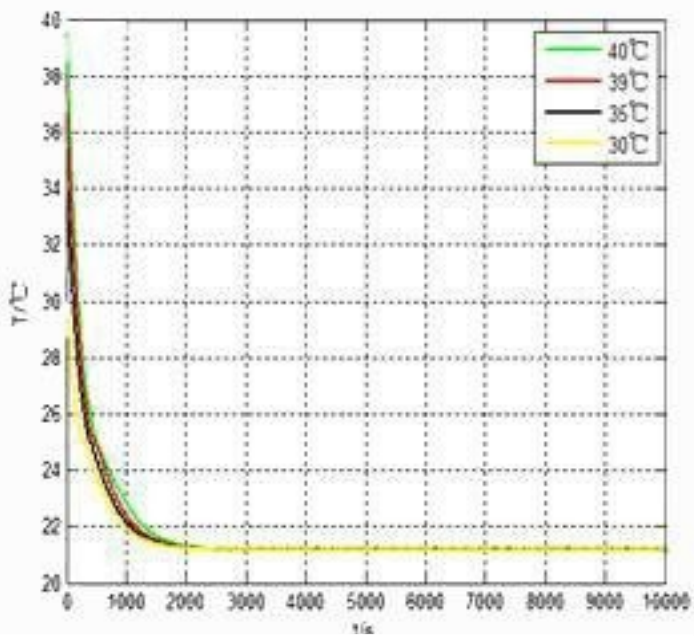

Figure5

In consideration of different initial temperature, the relationship between $t$ and $\mathrm{T}$, the button of bathtub is rectangle

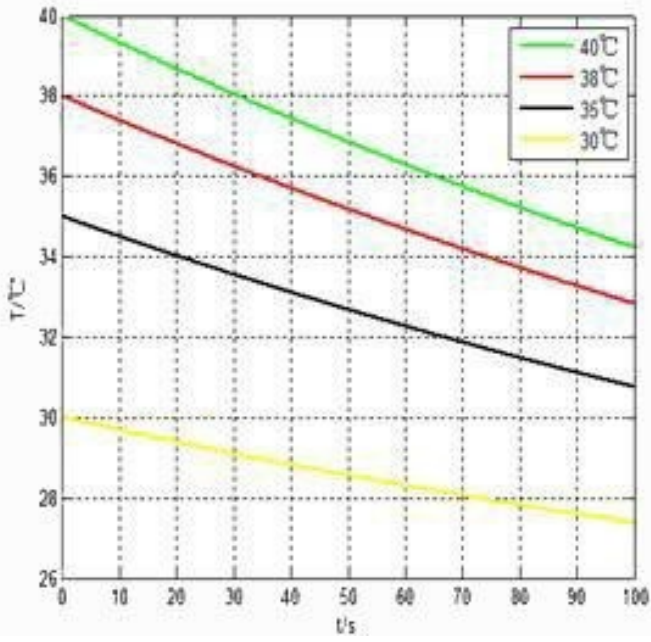

Figure6

the intercept graph of Figure5

We simulate the $t-T$ at the same initial temperature $\left(38^{\circ} \mathrm{C}\right)$, set a series of initial water volume. But the person in the bathtub doesn't move. The person's volume is $0.06 \mathrm{~m}^{3}$.

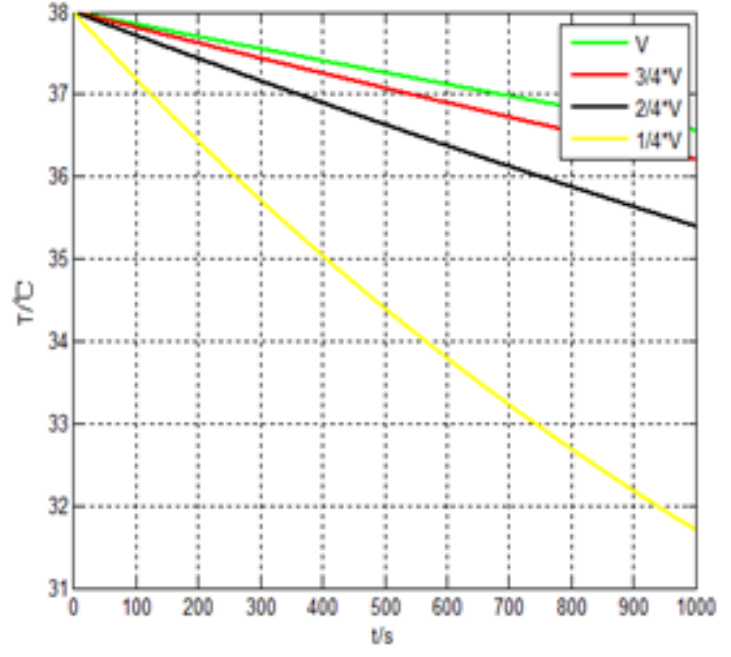

Figure7

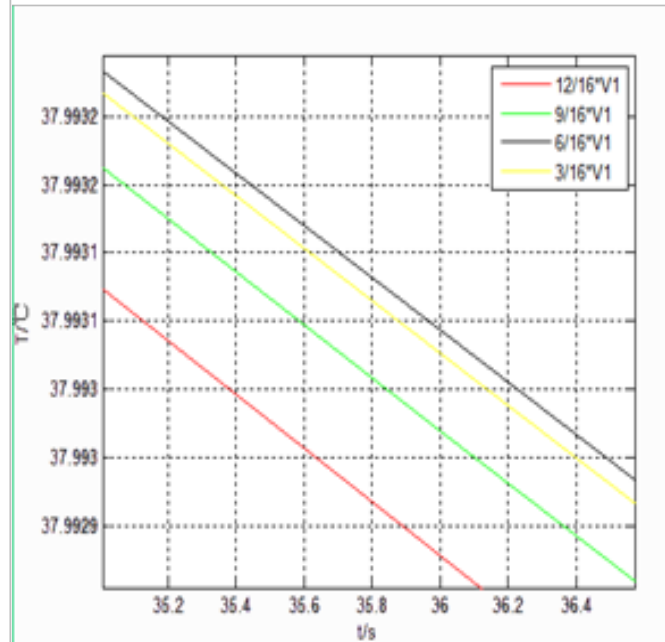

Figure8

The button of bathtub is roundness.

\section{Conclusion}

1) From the figure3 and 6, we can find that different initial temperature cool to the same ambient temperature if we don't add hot water into the original water. And they all cool rapidly and then change slowly.

2) We can easily conclude that initial temperature decides the cooling time. It is not too difficult to be understood.

3) By comparing the figure 3 and 4 we find that changing rate of temperature depends on the initial temperature. The changing rate becomes higher, as the initial temperature gets higher.

4) Except shapes of bathtub, we suppose the rest of the conditions are same. From the figure 3 and 5 , rectangle bathtub cools faster than columnar one. We can find better choice of shape.

5) Regardless of the motions made by the user, we can see the result that when the overall volume 
is $1 / 4 \mathrm{v}$, the changing of water temperature is slower than others. While the overall of volume is $3 / 4$, the changing of water temperature is faster than others. So we can infer that when the user submerges himself under the water, the temperature changing is different.

Results show that higher initial water temperature drops more slowly and the temperature of water changes faster in the columnar one. As for the motions of person, an impact factor of person is proposed to reflect the movement degree.

\section{References}

[1]. Vargaftik, N.B. Tables on the Therrmophysical Properties of Liquis and Gases 2nd. 